\title{
Study of the Painting Methods of Mural Paintings in Ancient Tombs of Goguryeo Using Scanning Electron Microscope
}

\author{
Kyeongsoon Han, ${ }^{1}$ Sangjin Lee, ${ }^{2}$ and Hwasoo Lee ${ }^{3, *}$ \\ ${ }^{1}$ Department of Conservation of Paintings, Konkuk University, Seoul 143-914, Korea \\ ${ }^{2}$ Seiyoung Conservation and Tech., Co. Ltd., Gyeongju 780-170, Korea \\ ${ }^{3}$ Department of Paintings, Konkuk University, Chungju 380-701, Korea
}

\begin{abstract}
Disputes on the painting methods of Goguryeo murals can mainly be categorized into whether the murals adapted eastern secco or western fresco; however, the murals have their own unique methods as well. There are different viewpoints among experts on interpreting the painting methods. This study involved the creation of research samples to discover the painting methods under dispute and may help discover the methods based on scanning electron microscopy energy-dispersive X-ray spectroscopy (SEM-EDX) studies. Goguryeo murals introduced pseudo-fresco rather than buon fresco methods. Unlike fresco techniques in the West, Goguryeo painters mixed traditional soft binders and adapted typical secco painting techniques for paintings, borders, and corrections after drying. The disputed issues may be resolved by these techniques, and samples may be produced based on the analyzed data. Therefore, many questions can finally be answered through SEM-EDX elemental mapping.
\end{abstract}

Key words: fresco, secco, mezzo fresco, Goguryeo mural techniques

\section{INTRODUCTION}

Studies on mural paintings in ancient tombs are valuable assets in the field of mural conservation and related academic fields. The mural painting method in the Goguryeo Dynasty consists of the Hwajangji production technique and the Joebyukji production method, depending on the walls being painted: lime finished walls and stone walls, respectively. The former, the so-called Hwajangji production technique, consists of the fresco and the secco methods, as well as a combination of the two, named the mezzo fresco technique. This classification is based on the representation of mural painting techniques in the West, and it is found that most murals in the East were produced by the secco method. Recently, there has developed an interest in studying the Goguryeo murals, and it has been found that some eastern murals adapted the fresco method, a representative mural painting method in the West. A fresco requires lime walls for painting; that is, the fresco is a method that uses features of lime. Lime was mainly discovered in ancient eastern tombs; however, there has been little research on their role in painting techniques. The Goguryeo murals have thus presented us with an opportunity to conduct such a study.

Investigated data state that the Hwajangji production techniques used in the Goguryeo murals are very advanced techniques for making walls. According to a UNESCO report by Rudolph Ruan in 1991, the first scientific investigation related to the Hwajangji production technique in Goguryeo murals, the murals were painted after applying

() MICROSCOPY SOCIETY OF AMERICA 2013

${ }^{\star}$ Corresponding author. E-mail: conservation@live.co.kr lime on stone pillars until the lime-covered walls had three layers with a 6-7 cm thick layer of lime (Lujan, 1991).

Lee Sang-soo and Ahn Byung-chan carried out scientific research on 12 murals in Ssangyeongchong and Tonggu for the first time in Korea in 1998 and proposed a low possibility for fresco murals based on the survey of the structural analysis and painting methods of the Hwajangji production technique in Goguryeo murals (Ahn, 2005).

A survey was conducted involving 31 murals in Hahaebang for the production method of lime walls, and it was proposed that the painting method in Goguryeo murals was a mixture of fresco and secco and that the murals represented an example of advanced techniques related to the media used and the mixing method (Ahn, 2003).

Professor Rocco Mazzo, an expert in pigment analysis and a member of the UNESCO Inspection Team of Mural Paintings of Pyeongyang Goguryeo in 2004 conducted a survey on mural samples in Deokheungri to explain the painting methods and concluded that Goguryeo murals were fresco paintings and that the samples were similar to murals in Europe (Mazzo, 2004).

In 2005, samples like Ssangyeongchong were added and the analysis results were announced. Here, it was discovered that red-colored swollen pigments were used, and it was highly possible to have media for pigment attachment, with each pigment being painted after applying white flakes to places with pictures, implying that the secco, rather than the fresco method, was introduced (Yu, 2005).

The summary of painting methods mentioned in tomb 1 and 4 in Jinpari near Pyeongyang conducted by the two Koreas in 2007 is as follows: no sample was found appropriate for a precise analysis of the painting methods in Tomb 1 , 


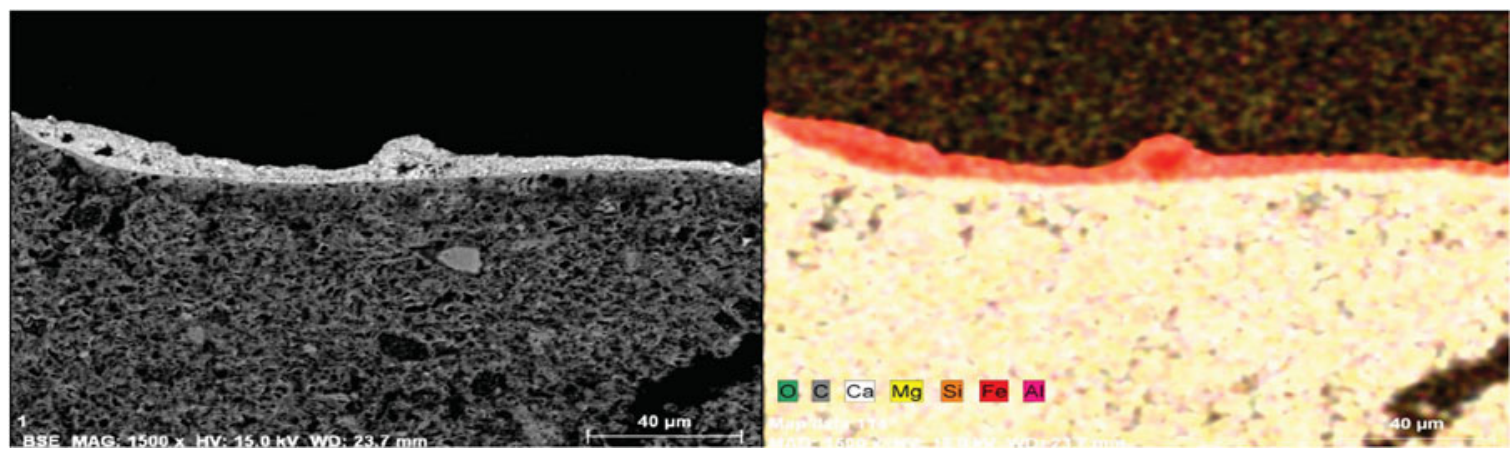

Figure 1. SEM-EDX elemental mapping of Sample A. SEM, scanning electron microscopy; EDX, energy-dispersive $\mathrm{X}$-ray spectroscopy.

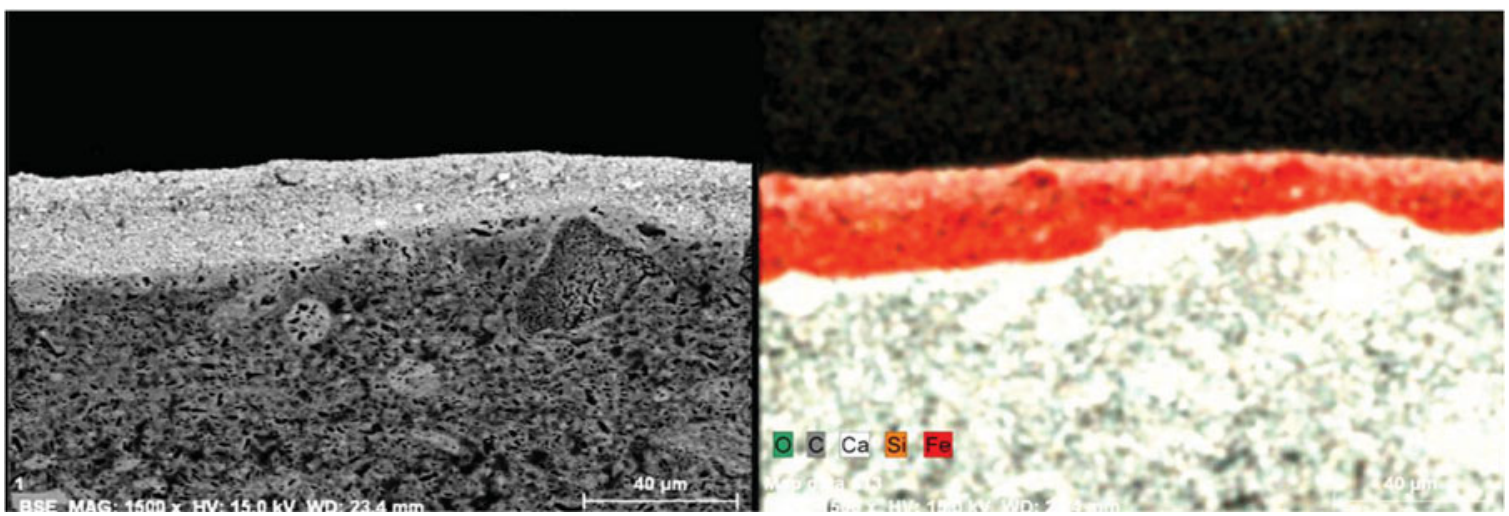

Figure 2. SEM-EDX elemental mapping of Sample B. SEM, scanning electron microscopy; EDX, energy-dispersive $\mathrm{X}$-ray spectroscopy.

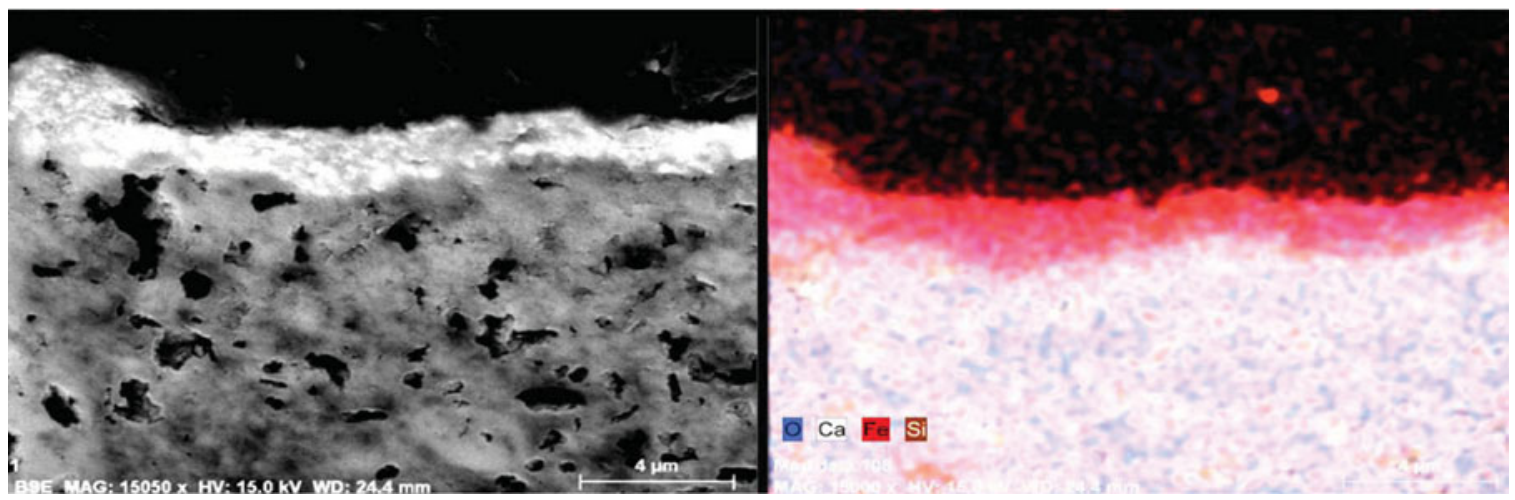

Figure 3. SEM-EDX elemental mapping of Sample C. SEM, scanning electron microscopy; EDX, energy-dispersive $\mathrm{X}$-ray spectroscopy.

and caution was taken in concluding, based on inspection with the naked eye, that patterns were found suggestive of the fact that some pictures were drawn by the fresco method. One of the most interesting points is that there is a deep hole in the center of a picture of a lotus flower on a black ceiling, which might have been used to draw a circle. It is difficult to bore a hole in dried lime, and it is believed that a skilled Goguryeo painter would have had no intention to drill an unnecessary hole. On the basis of these facts, the holes might have been used to draw circles on wet lime walls, and a certain amount of labor might have been involved in preparing the paintings before the walls dried. These features have been discovered in Deukheung-ri ancient murals (Kim, 2006).

There are different viewpoints among experts on interpreting the painting methods. Disputes on the painting methods of Goguryeo murals can mainly be categorized into whether the murals adapted eastern seccos or western frescoes; however, the murals have their own unique methods as well. This study involved the creation of research samples to discover the painting methods under dispute and may help discover the methods based on scanning 


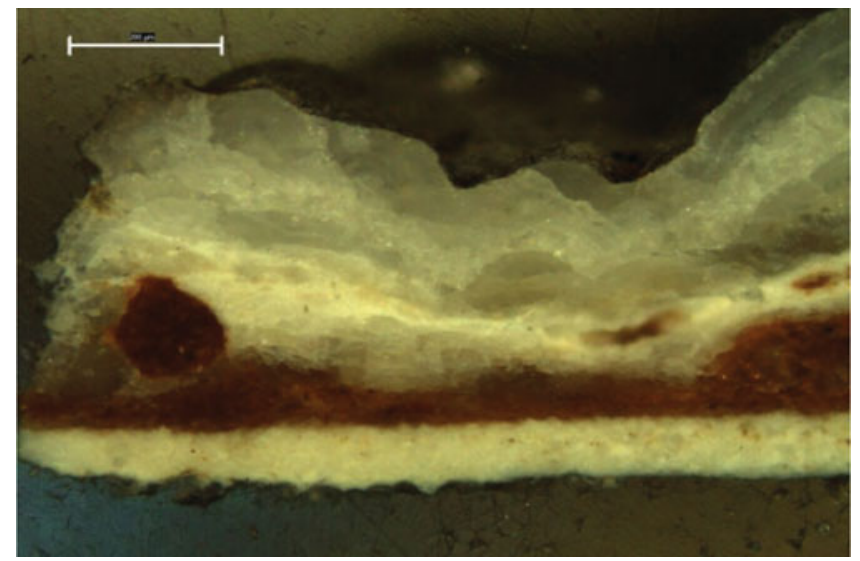

Figure 4. Jinpari No. 1-1 cross-section of the pigment layer.

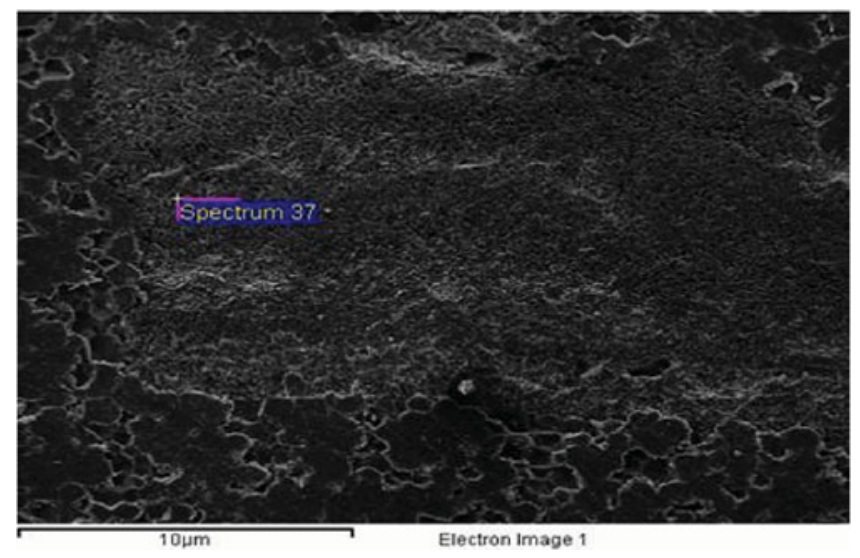

Figure 5. Microstructure of the outer pigment layer.

electron microscopy energy-dispersive X-ray spectroscop (SEM-EDX) studies.

\section{Experimental Method}

Studies on the production techniques of Goguryeo murals have reported on the lime-processing methods, the use of mixed materials to form walls, and their structural features. The plaster used to form walls for murals has a stable structure with three layers including preliminary, intermediary, and finished ones. This study intended to investigate these painting techniques; therefore, samples were manufactured by forming a finished layer and painting over it. Most Goguryeo murals are composed of pure lime with no mixes for finishing. In this study, a layer was formed using highly pure lime, and test sample layers were produced over this layer. The painting techniques were verified using crosssections of the samples through SEM-EDX elemental mapping. The eastern seccos have clear borders between the pigment and finished layers. In contrast, the western frescos involve the formation of calcium carbonate films on the pigment layer, and a part of the layer is permeated into the finished one. The mixed painting technique, which has emerged as a new possibility, may be investigated by producing samples. In the case that the result is the most similar compared to research data on previous mural samples, it may show the highest possibility as a painting technique for the Goguryeo murals.

\section{Producing Samples}

The finished lime layer in the murals was produced using cakes with qualified slaked lime based on inspection of the samples taken from the site, measuring their hardness, and performing XRF, XRD, and SEM-EDX. Moreover, hematite $\left(\mathrm{Fe}_{3} \mathrm{O}_{4}\right)$ was used for painting (Han \& Lee, 2006).

The samples were produced using three techniques: Sample A was painted with 5\% glue and red pigment on a dried lime surface, Sample B was painted with water and red pigment on a wet lime surface, and Sample C was painted with $2 \%$ glue and red pigment on a wet lime surface. The Danyang Lime Research Center provided the lime and IKOMA, Japan, provided the pure glue for the samples.

\section{Results AND Discussion}

Distinguishing the painting methods of Goguryeo murals in ancient tombs on secco or fresco techniques is not possible; this is because both secco and fresco are possibilities and are similar to the mezzo fresco technique, which is intermediate between the the two methods; however, there are clear differences. We may say that these murals show similarities with western mural paintings, as well as distinct differences. Therefore, the painting techniques of these murals can be described as being unique to Goguryeo or eastern mural paintings.

The cross-sections of the samples on SEM-EDX show elemental mapping, and film structures between the secco and the fresco have clear contrasts. Sample A (Fig. 1) had clear borders between the lime and the paint layers and Sample B (Fig. 2) had calcium films on the painted layer, implying that calcium was present on a part of the layer. Sample C (Fig. 3), which was painted with the fresco technique using a low concentration of glue with mixed techniques, showed no clear differences from the fresco and firm painted layers because of pigment penetration into the lime layer. Western frescos do not use binding materials; however, the eastern technique uses animal glues for painting. Considering that Goguryeo painters were capable of painting by adjusting the glue concentration and used advanced techniques in lime processing, it is assumed that it was not easy to implement the secco technique on wet surfaces. That is, it might be possible in the case of having advanced techniques in handling lime mortar and eastern traditional painting techniques. Sample $\mathrm{C}$ showed a high similarity to the Goguryeo murals and might have been the technique used in these murals.

This study revealed that Sample C was composed of fine calcium carbonate films on the painted layer, a feature of the fresco technique. This is mainly because glue with a low concentration was used for painting, and the technique had significantly less films than those in a fresco. However, 


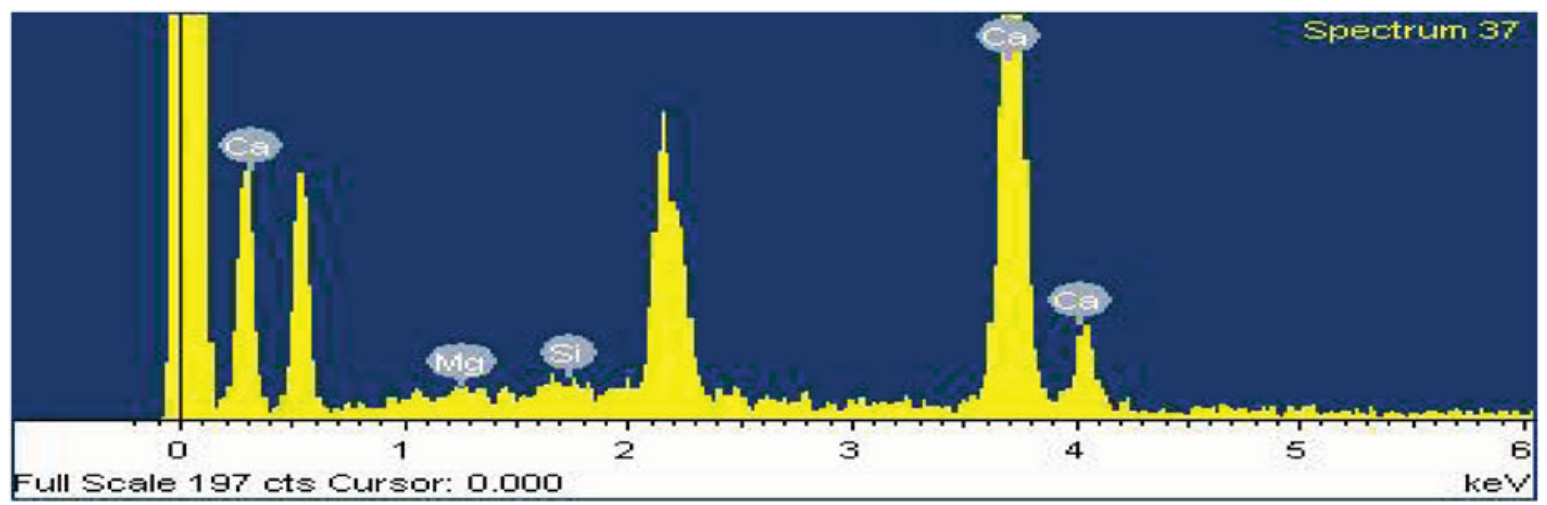

Figure 6. EDX spectrum of the outer layer from Jinpari No. 1-1. EDX, energy-dispersive X-ray spectroscopy.

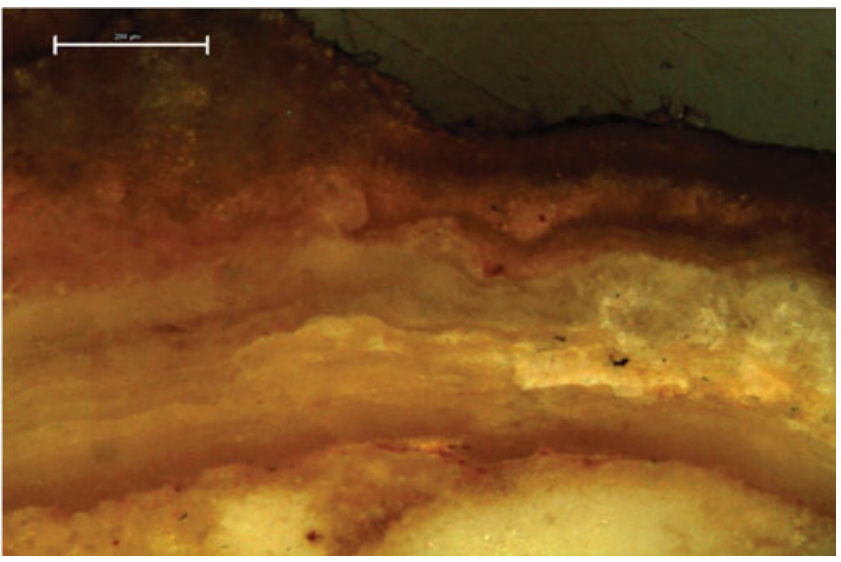

Figure 7. Jinpari No. 1-2 cross-section of the pigment layer.

as shown in many samples of Goguryeo murals, there were clear calcium carbonate films on the surface, a feature of the fresco technique. Considering this reason, several studies have concluded that the murals adapted western fresco techniques. However, we discovered errors in these conclusions on the basis of the analysis of the calcium carbonate layers commonly discovered on the surfaces of Goguryeo murals.

In 2007, a study observed mural samples collected from Jinpari No. 1, which were produced in the 6th century. The brown-black samples collected were observed through a metal microscope and SEM and analyzed by EDX. The white films on the samples collected from Jinpari No. 1 were composed of white and red-brown translucent layers from the bottom according to their cross-sections obtained by metal microscopes. The two bottom layers were assumed as painted layers on the basis of the border surface or slices. The contaminants formed layers of milk-white, white, and

Table 1. Elemental Content of the Outer Layer from Jinpari No. $1-1$.

\begin{tabular}{lcc}
\hline & Element (wt\%) & \\
\hline $\mathrm{MgO}$ & $\mathrm{SiO}_{2}$ & $\mathrm{CaO}$ \\
\hline 1.46 & 0.6 & 97.39 \\
\hline
\end{tabular}

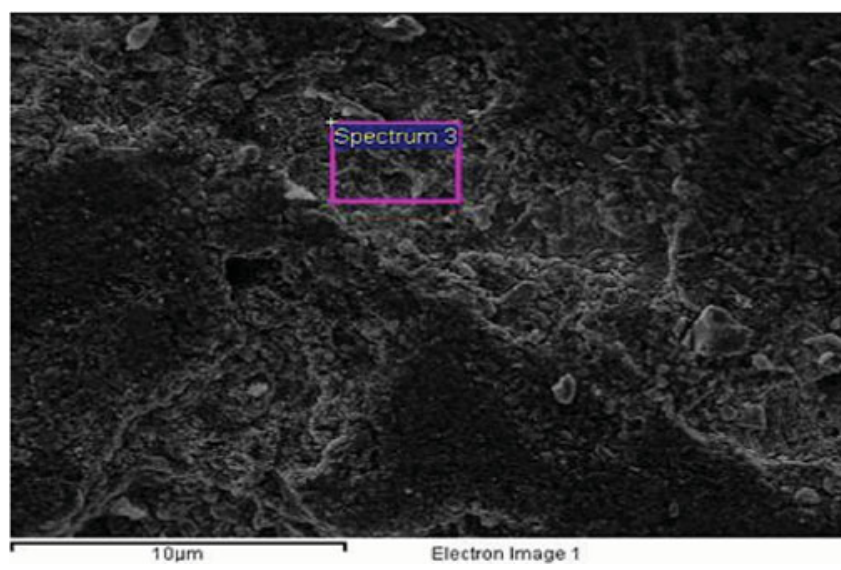

Figure 8. Microstructure of the outerpigment layer.

gray-white colors on the top (Fig. 4). These layers may be shown in images taken from the SEM (Fig. 5). The third layer was shown to be mainly composed of calcium (97.93\%) through EDX analysis (Fig. 6; Table 1).

The cross-sectional image from the optical microscope showed wave-shaped brown or brown-black layers (Fig. 7), and it was discovered that the layers mainly consisted of calcium, silica, and iron, according to the element analysis of EDX, which involves enlarging the central part of the image through SEM (Figs. 8, 9). It is assumed that the contaminated layer on the surface was formed by soil that contained iron, $\mathrm{CaSO}_{4}$, or $\mathrm{CaCO}_{3}$ (Table 2).

On the basis of the data given above, the white films from Jinpari No. 1 and No. 4 were mainly composed of $\mathrm{CaSO}_{4}$ and $\mathrm{CaCO}_{3}$ (Han \& Lim, 2008).

As for the weather condition inside the ancient tombs containing the Goguryeo murals distributed around Pyeongyang, the temperature is $10-15^{\circ} \mathrm{C}$ and the relative humidity

Table 2. Elemental Content of the Outer Layer from Jinpari No. 1-2.

\begin{tabular}{lcccc}
\hline \multicolumn{5}{c}{ Element $(w t \%)$} \\
\hline $\mathrm{Al}_{2} \mathrm{O}_{3}$ & $\mathrm{SiO}_{2}$ & $\mathrm{~K}_{2} \mathrm{O}$ & $\mathrm{CaO}$ & $\mathrm{Fe}_{2} \mathrm{O}_{3}$ \\
\hline 12.24 & 39.68 & 2.95 & 36.54 & 8.61 \\
\hline
\end{tabular}




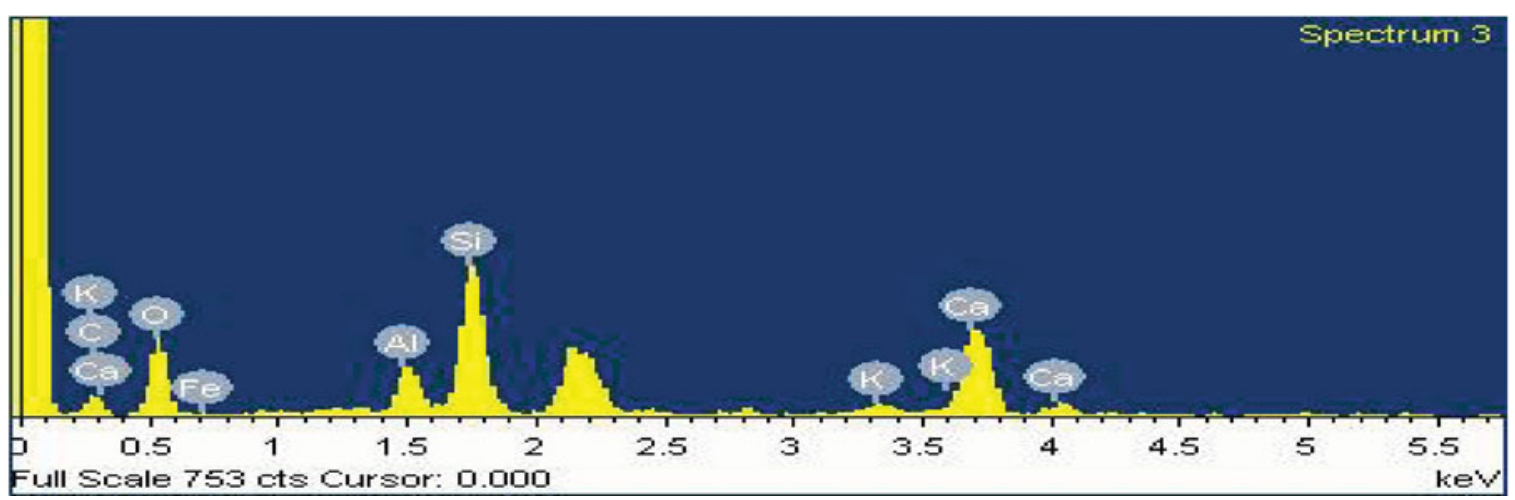

Figure 9. EDX spectrum of the outer layer from Jinpari No. 1-2. EDX, energy-dispersive X-ray spectroscopy.

is higher than $90 \%$. It may be assumed that the white film or slice contaminants on the mural surfaces had very low solubility. The positive and negative ion analyses of the diffused water on the surfaces reported that $\mathrm{Ca}^{2+}$ and $\mathrm{SO}_{4}^{2-}$, respectively, were abundant in the water (Chung, 2006). This implies that it is highly possible for $\mathrm{CaSO}_{4}$ to be formed on the mural surfaces as slices. Moreover, white films and sliced contaminants mainly composed of $\mathrm{CaSO}_{4}$ and $\mathrm{CaCO}_{3}$ form on murals in presence of high humidity.

In conclusion, it is hard to say that the white calcium carbonate films discovered on the Goguryeo murals formed at the time of painting. Rather, they have been formed under the environmental conditions of the tombs over a long period of time.

\section{CONCLUSION}

Distinguishing the painting methods of Goguryeo murals in ancient tombs on secco or fresco techniques is not possible; this is because evidences of a mixed painting technique of secco and fresco have been largely discovered. This technique is called mezzo fresco and is the most similar with the Goguryeo murals in terms of characteristics. A western mezzo fresco is created by mixing water and pigments and applying adhesives after drying. However, the Goguryeo murals feature paintings created by mixing glue at a low concentration. The secco method involving lime walls incorporates techniques of using glue. Thus, it can be assumed that this technique was used in Goguryeo's traditional mural painting techniques or eastern mural techniques. Thus, we may conclude that these murals harbor similarities with western mural paintings, as well as distinct differences.

Goguryeo murals introduced pseudo-fresco rather than buon fresco methods. Unlike fresco techniques in the West, Goguryeo painters mixed traditional soft binders and adapted typical secco painting techniques for paintings, borders, and corrections after drying. The disputed issues may be resolved by using these techniques, and samples may be produced based on the analyzed data. Therefore, many questions can finally be answered through SEM-EDX elemental mapping.

\section{REFERENCES}

Ahn, B. (2003). Study on Painting Techniques of Ancient Murals in the Goguryeo Dynasty-Manufacturing Painting Walls, vol. 16. Seoul: Association of Koguryo Balhae.

Aнn, B. (2005). Study on manufacturing techniques of Goguryeo ancient tombs. International Symposium, Mural Painting from the Gogury Kingdom, Germany.

Chung, Y. (2006). Survey on biology and environment of Mural in Goguryeo Tombs. Survey Report on Conservation Status of Goguryeo Murals by the Two Koreas. Daejeon: National Research Institute of Cultural Heritage.

Han, K. \& Lee, H. (2006). Study on lime layers in murals in ancient Goguryeo Tombs. Conservation Science, vol. 19. Gongju: The Korean Society of Conservation Science for Cultural Heritage.

Han, K. \& Lim, K. (2008). Study on removal of brownish black and white crust mural in Goguryeo Tombs. Conservation Science, vol. 22. Gongju: The Korean Society of Conservation Science for Cultural Heritage.

Kim, S. (2006). Survey on Conservation Status of Mural in Goguryeo Tombs. Survey Report on Conservation Status of Goguryeo Murals by the Two Koreas. Daejeon: Natoinal Research Institute of Cultural Heritage.

Lujan, R. (1991). The Conservation of Mural paintings. Serial No. FMR/CTL/CH/91/102. Paris: UNESCO.

Mazzo, R. (2004). Scientific examination of mural paintings of the Goguryeo ancient tombs. International Symposium on the Conservation and Restoration of Cultural Properties. NRICP, Tokyo.

Yu, H. (2005). Pigment analysis of Ssangyeongchong murals. Museum Conservation Science, vol. 6. Seoul: National Museum of Korea. 